\title{
Correction to: Laparoscopic Cholecystectomy for Acute Cholecystitis: Is the Surgery Still Safe beyond the 7-Day Barrier?
}

\author{
Ismael Mora-Guzmán ${ }^{1}$ • Marcello Di Martino ${ }^{1}$ - Alvaro Gancedo Quintana ${ }^{1}$ • Elena Martin-Perez ${ }^{1}$ \\ Published online: 25 November 2020 \\ (C) 2020 The Society for Surgery of the Alimentary Tract
}

\section{Correction to : Journal of Gastrointestinal Surgery https://doi.org/10.1007/s11605-019-04335-5}

There is a revision in a section of this published paper, the corrected paragraph is below:

\section{Methods}

\section{Patients and Characteristics}

This is a single-institution retrospective observational study of patients who underwent ELC for ACC. The data included consecutive patients operated on from January 2010 to September 2018 with the following inclusion criteria: (1) diagnosis of ACC defined according to the Tokyo Guidelines criteria (including local signs with Murphy's sign and right upper quadrant mass/pain/tenderness and systemic signs with fever, elevated C-reactive protein, and elevated white blood cell count); 1, 10, 11, (2) ELC performed during the index admission for an ACC; and (3) surveillance up to minimum of 30 postoperative days. Exclusion criteria were (1) presence of another concomitant acute biliary pathology (cholangitis, choledocholithiasis, and acute pancreatitis) and (2) acute cholecystitis not related to a gallstone aetiology (like acalculous cholecystitis and biliary malignancy).

Publisher's Note Springer Nature remains neutral with regard to jurisdictional claims in published maps and institutional affiliations.

The online version of the original article can be found at https://doi.org/ 10.1007/s11605-019-04335-5

Marcello Di Martino

marcellodima@gmail.com

1 Department of General and Digestive Surgery, Hospital Universitariode la Princesa, Diego de León Street, 62-4th Floor, 28006 Madrid, Spain 